\title{
Minimally Invasive Percutaneous Pedicle Screw Fixation for Thoracolumbar Spine Fractures: Case Report and Review of Literature
}

Kaisorn L. Chaichana*, Rafael De la Garza-Ramos, Daniel M. Sciubba, Ziya L. Gokaslan and Ali A. Baaj

Department of Neurosurgery, The Johns Hopkins School of Medicine, USA

\begin{abstract}
Study background: Thoracolumbar fractures are among the most common type of traumatic spine fractures. The use of minimally invasive, percutaneous pedicle screw fixation for these fractures has been limited to case reports and small case series. The efficacy of this approach remains unclear.

Methods: The evaluation and management of a patient with traumatic T12 burst fracture is presented. In addition, a literature review of the Medline and PubMed databases was conducted.

Results: A total of 166 patients from 8 studies were identified. Average age was 46 years. Polytrauma was reported in $27 \%$ of patients. Average surgery time was 91 minutes, with an average blood loss of 95 milliliters. Reported complications were non-healing fracture in $3(2 \%)$, infection in $1(0.6 \%)$, mal-positioned screw in $1(0.6 \%)$, and hematoma in $1(0.6 \%)$ at a median follow-up time of 26 months. Pain improved by an average of 6 points after surgery according to visual analog score, and mean kyphosis correction in these studies was $8.5^{\circ}$.

Conclusions: This review demonstrates that minimally invasive, percutaneous pedicle screw fixation is a viable option for the management of traumatic thoracolumbar fractures in neurologically intact patients. Patients who are older and/or present with polytrauma may most benefit from this type of intervention.
\end{abstract}

Keywords: Minimally invasive, Pedicle fixation, Spinal trauma, Thoracolumbar

\section{Introduction}

Traumatic thoracolumbar fractures are among the most common spine injuries [1,2]. Despite their commonality, management of unstable thoracolumbar fractures remains controversial. Conservative approaches namely bracing and/or bedrest are associated with continued pain, residual and possibly progressive kyphosis, and late neurological impairment $[1,2]$. Operative approaches involve placement of short- or long-segment fusion as well as pedicle fixation or internal bracing to restore alignment and preserve neurological function $[1,2]$. These interventions are not usually tolerated by older individuals with significant medical co-morbidities and patients who have suffered polytrauma $[1,2]$. This limitation has led to the development of minimally invasive techniques, namely percutaneous pedicle screw fixation [3-5]. This technique is believed to have the advantages of typical open operative approaches including restoration of sagittal alignment and stabilizing fractures without the associated morbidities of open exposures and long operative times [3-5]. Potential downfalls of this approach include loss of fixation, delayed kyphosis, and non-healing of the fracture [3-5].The efficacy of percutaneous pedicle screw fixation, however, for traumatic thoracolumbar fractures remains unclear.

The aim of this study was to describe a case where minimally invasive percutaneous pedicle fixation was used for a debilitated patient with rapid progressive dementia, and review the literature on the efficacy of this approach for traumatic thoracolumbar fractures. The literature on this approach has been primarily limited to case series and case reports [3,6-14]. A better understanding of the clinical outcomes for patients who underwent percutaneous pedicle fixation (i.e. internal bracing) following traumatic thoracolumbar fractures may help guide treatment regimens aimed at maximizing patients outcomes and minimizing surgical morbidity. This is especially important for patients who typically cannot tolerate open surgery including older patients, patients with multiple co-morbidities, and patients with polytrauma.

\section{Case Report}

\section{History}

A 69-year-old male with a history of frontotemporal dementia, Alzheimer's disease, and hypertension presented after falling from a ladder at a height of 10 feet. Following the fall, he complained of lower back pain and bilateral radiating pain from his back to the posterior aspect of his calves. He was brought to our institution for evaluation and management.

\section{Examination}

Upon arrival, he was at his neurological baseline. He was awake, alert, oriented to self, but confused to date and location. He had full strength throughout his bilateral upper and lower extremities. He had intact sensation to pinprick including his bilateral lower extremities. His reflexes were $2+$ in his bilateral patella and ankle reflexes, with no clonus and downward Babinski reflexes. He also had intact proprioception in his bilateral lower extremities. He had intact rectal sensation and tone. He did, however, complain of 7/10 back pain on the

*Corresponding author: *Corresponding author: Kaisorn L. Chaichana, Department of Neurosurgery, The Johns Hopkins Hospital, 600 North Wolfe Street, Meyer 8-161, Baltimore, Maryland 21287, USA, Tel. 410-262-7828; Fax: 410-502-5559; E-mail: kaisorn@jhmi.edu

Received April 16, 2012; Accepted May 10, 2012; Published May 12, 2012

Citation: Chaichana KL, la Garza-Ramos RD, Sciubba DM, Gokaslan ZL, Baaj AA (2012) Minimally Invasive Percutaneous Pedicle Screw Fixation for Thoracolumbar Spine Fractures: Case Report and Review of Literature. J Trauma Treat 1:134. doi:10.4172/2167-1222.1000134

Copyright: (C) 2012 Chaichana KL, et al. This is an open-access article distributed under the terms of the Creative Commons Attribution License, which permits unrestricted use, distribution, and reproduction in any medium, provided the original author and source are credited. 
Citation: Chaichana KL, la Garza-Ramos RD, Sciubba DM, Gokaslan ZL, Baaj AA (2012) Minimally Invasive Percutaneous Pedicle Screw Fixation for Thoracolumbar Spine Fractures: Case Report and Review of Literature. J Trauma Treat 1:134. doi:10.4172/2167-1222.1000134

visual analog scale (VAS), and this pain was increased upon palpation of his spinous processes in the T10-L1 region. He also complained of radiating pain from his back to his buttocks to the posterior aspect of high thighs.

The patient underwent a head, complete spine (cervical/thoracic/ lumbar), chest, abdomen, and pelvis computed tomography (CT) scans because of the nature of his fall. The CT scans were negative for any acute process, with the exception of his thoracic spine CT. This CT revealed a burst fracture of the T12 vertebral body (AO class 3.3), with retropulsion of bone fragments into his spinal canal (Figure 1). This retropulsion caused moderate stenosis of his spinal canal. A magnetic resonance image (MRI) was not pursued because of his intact neurological exam and minimal kyphosis.

\section{Treatment}

The patient was observed overnight in the neuro-intensive care unit and taken to the operating room the following day for percutaneous T11-L1 pedicle fixation/internal fixation. Pre-operative motor (MEP) and somatosensory evoked potentials (SSEP) were obtained prior to placing the patient the prone. The patient was then placed prone in a radiolucent T3 frame. MEP and SSEP were obtained once again, and remained stable. Anterior-posterior (AP) and lateral fluoroscopes were brought into the field to help with localization. After determination of the correct operative levels, the area was prepped with betadione. The surgical area was then draped in sterile fashion.

A $2 \mathrm{~cm}$ paramidline incision was made overlying the right transverse process (TP)-facet junction at L1 (Figure 2). The underlying fascia was undermined with Bovie cautery. A Jamshidi needle was docked at the transverse process-facet junction at L1, as confirmed by fluoroscopy. The Jamshidi needle was gently advanced with the use of a mallet, and location of the needle within the pedicle was confirmed with AP and
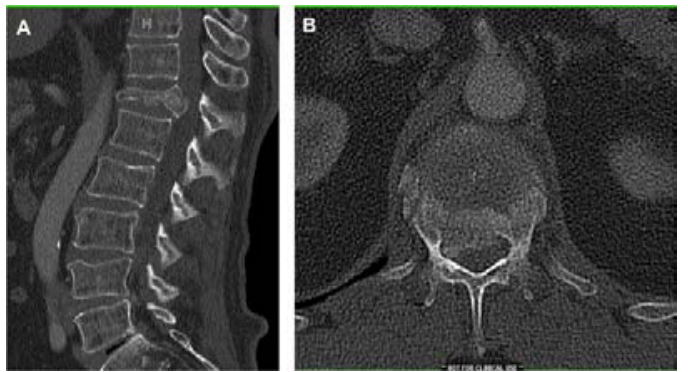

Figure 1: Pre-operative computed tomography (CT) scans. A, Sagittal and B axial CT images demonstrating a T12 burst fracture in a 65 -year-old patient following a fall from a ladder.

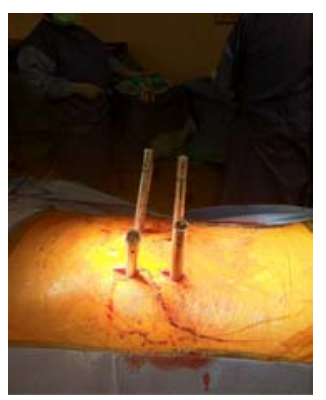

Figure 2: Intra-operative image. Intra-operative image demonstrating the placement of percutaneous towers via four small stab incisions. lateral fluoroscopy (Figure 3). Advancement of the Jamshidi needle is driven by AP and lateral fluoroscopy to ensure proper placement and to make sure it is not too medial. As the needle traverses the pedicle on lateral $\mathrm{x}$-ray, the AP $\mathrm{x}$-ray was used in correlation to make sure the medial aspect of the pedicle is not compromised as the needle is advanced until it reaches the vertebral body. Once entering the vertebral body, a K-wire was advanced through the Jamshidi. The Jamshidi was subsequently removed, leaving the K-wire in place. The same process was repeated on the left side for L1, and bilateral T11 pedicles. This resulted in K-wires in the T11 and L1 pedicles bilaterally.

Following placement of the K-wires, a tapping instrument was passed over the K-wires. $6.0 \times 45 \mathrm{~mm}$ pedicle screws (Depuy Viper MIS, Warsaw, IN) were placed at T11 and L1 bilaterally under fluoroscopic visualization. The screws were stimulated with EMG and an intraoperative CT scan was done to confirm placement of the pedicle screws in the pedicles (Figure 4). Rods were then placed bilaterally by inserting the rods subfascially from cephalad to caudal, and secured with the use of towers. The rods were held in place with caps on the T11 and L1 pedicle screws. No distraction was done. Final AP and lateral x-rays were performed. Final MEP and SSEPs were also performed and were at the pre-operative baseline. The $4,2 \mathrm{~cm}$ paramedian incisions were closed in standard fashion. The operative time was 65 minutes, and the estimated blood loss was $75 \mathrm{cc}$.

After completion of the operation, the patient was returned to the supine position. He was awoken, moved all four extremities with good strength, and was extubated. He was allowed to recover in the ICU. He was mobilized on post-operative day one, and was discharged to a rehabilitation center on post-operative day 5 . His pain on discharge was $2 / 10$. His neurological exam was full strength in his bilateral lower extremities. His kyphosis correction was measured at $6^{\circ}$.

\section{Outcome}

Two months after spinal fixation surgery, the patient suffered another fall while at rehabilitation center and fractured his hip, requiring hip surgery. One month later, he was seen in follow-up in our office. His dementia had progressed significantly and was now wheel chair bound, though he appeared to have full strength in his lower extremities. Neurology projected that his survival was approximately 3 months. His pain score was $1 / 10$. Dynamic $x$-rays taken at this threemonth postoperative visit confirmed good position of the hardware, evidence of fracture healing, and no evidence of instability or loss of correction (Figure 5).

\section{Review of the Literature}

A literature search of the Medline and PubMed databases was conducted using the key words: "trauma," "thoracolumbar," "fusion," and "fixation." All papers written in English up to December 2011 were reviewed. The studies that were included were studies involving traumatic thoracolumbar fractures using percutaneous pedicle fixation. Studies involving pedicle fixation for degenerative spine disease were excluded. Additionally, studies written primarily in a different language other than English were excluded. The information collected from each study included number of patients, etiology, level of spinal fracture, fracture type according to the $\mathrm{AO}$ spine classification [15], presenting neurological symptoms, complications of surgery, and outcomes. The outcome measures evaluated include pain, neurological symptoms, and kyphosis correction.

Eight studies with the use of internal fixation (non-fusion) met the inclusion criteria (Table 1) $[6-12,14]$. The total number of patients was 
Citation: Chaichana KL, la Garza-Ramos RD, Sciubba DM, Gokaslan ZL, Baaj AA (2012) Minimally Invasive Percutaneous Pedicle Screw Fixation for Thoracolumbar Spine Fractures: Case Report and Review of Literature. J Trauma Treat 1:134. doi:10.4172/2167-1222.1000134
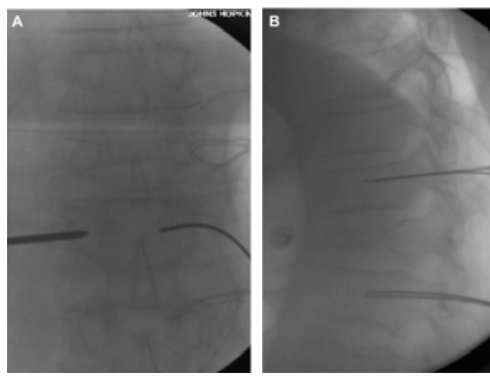

Figure 3: Intra-operative x-rays. A, Anterior-posterior and B, lateral x-rays demonstrating localization of the pedicle using intra-operative fluoroscopy.
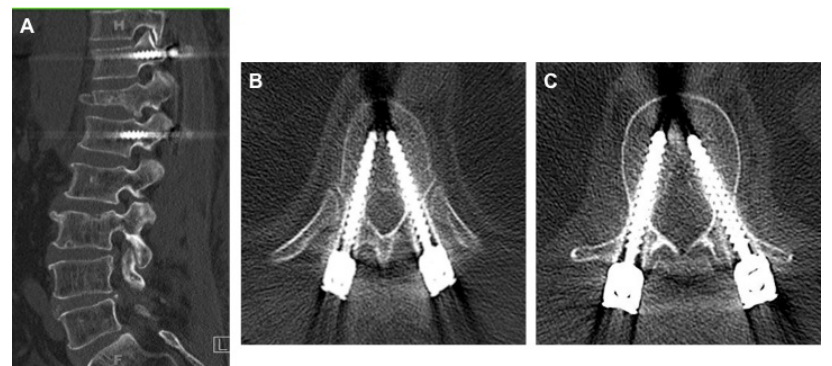

Figure 4: Post-operative computed tomography (CT) scans demonstrating T11-L1 pedicle fixation using minimally invasive, percutaneous techniques. A Sagittal and B, axial CT.

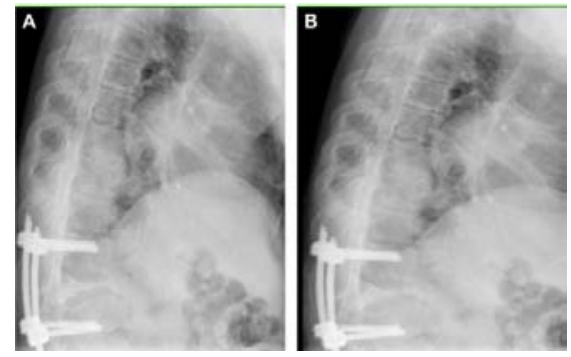

Figure 5: Flexion-extension x-rays at last follow-up following a fall requiring hip surgery. Instrumentation remained intact. A, Anterior-posterior and B, latera x-rays.

166 patients. The number of patients in each study ranged from 1 to 51 . The average age of the patients was 46 years, with a range from 16 to 88 . The etiology of the spinal fractures can be divided into two categories: fall from height and motor vehicle collision (MVC). Of the 117 patients with reported etiologies, 61 (52\%) sustained thoracolumbar fractures from a fall and $56(48 \%)$ from a motor vehicle collision. Polytrauma was reported in 23 (27\%) of the 85 patients in studies where polytrauma was assessed. The location of the fractures was T9 in 1 (1\%), T10 in 0 (0\%), T11 in 7 (7\%), T12 in 17 (18\%), L1 in 42 (44\%), L2 in 18 (19\%), L3 in 4 (4\%), L4 in $3(3 \%)$, and L5 in $3(3 \%)$ patients. According to the AO spinal fracture classification [15], the fractures could be classified as A1 in $21(12 \%), \mathrm{A} 2$ in 12 (7\%), $\mathrm{A} 3$ in $132(75 \%), \mathrm{B} 1$ in $1(1 \%), \mathrm{B} 2$ in $6(3 \%)$, $\mathrm{C} 1$ in $1(1 \%)$, and $\mathrm{C} 2$ in $2(1 \%)$ patients. One $(0.7 \%)$ of the patients with reported symptoms had weakness. The average (range) surgery time of all of the studies was 91 (45-210) minutes, with an average (range) blood loss of 95 (50-22) milliliters. The reported complications were non-healing fracture in $3(2 \%)$, infection in $1(0.6 \%)$, mal-positioned screw in $1(0.6 \%)$, and hematoma in $1(0.6 \%)$ requiring evacuation at a median (range) follow-up time of 26 (1-85) months.
The outcome characteristics that were assessed were pain, neurological symptoms, and kyphosis. Only three studies assessed pain scores before and after surgery $[7,8]$. According to the visual analog score (VAS), the pain improved by an average of 6 points after surgery. The only patient who presented with neurological symptoms regained complete neurological function after surgery [6]. Pre- and post-operative kyphosis was assessed in 7 studies [7-12,14]. The mean kyphosis correction in these studies was $8.5^{\circ}$.

\section{Discussion}

A number of techniques have been described in the management of thoracolumbar spine fractures [3,5,16-18]. This abundance of techniques indicates a lack of consensus in the management of patients with these relatively common injuries [1-3]. Management ranges from conservative management to open surgical procedures [1-3] Conservative management entails bedrest, brace, and/or cast placement [1-3]. While some patients may benefit from this management, many patients require prolonged bedrest which is not feasible for the majority of patients. In addition, patients may suffer from prolonged pain, progressive spinal instability, and occasionally neurological compromise [1-3]. Many different surgical techniques have also been described via posterior, anterior, or combined approaches to manage thoracolumbar fractures. These open surgical techniques, while not uniform, aim to correct deformity, stabilize the spine, and preserve neurological function [3,5,16-18]. These techniques include short segment posterolateral fusion, long segment posterolateral fusion which can extend three levels above and below the fracture, and corpectomy with posterolateral fusion, among others. These traditional fusion techniques, however, require extensive exposure, which can be associated with significant morbidity $[3,5,16-18]$. This morbidity includes high intra-operative blood loss, prolonged surgery times, increased infection rates, and paraspinal muscle denervation or injury $[3-5,10,12]$. These additional risks associated with open surgery may not be well tolerated in certain patient populations including older patients, patients with multiple co-morbidities, and polytrauma patients, among others.

This need for spinal fixation in patients who cannot tolerate typical open surgery has led to the development of minimally invasive surgery, namely percutaneous pedicle screw fixation. Roy-Camille first reported the use of pedicle screws in 1963 [19]. Since this initial report, the use of pedicle screws during open surgery to fuse short-segments surrounding a fracture site has been a well-accepted treatment for unstable thoracolumbar fractures [3,5,16-18]. Margerl later developed the technique of percutaneous pedicle screw placement in 1977 [5]. These pedicle screws were primarily used for temporary fixation, and later removed [5]. Until recently, the techniques of percutaneous pedicle screw fixation have been primarily used as supplemental fusion combined with minimally invasive posterior or anterior lumbar interbody fusion in the management of degenerative lumbar disease [1-3]. With advances in surgical technique and equipment, there have been an increasing number of studies documenting the efficacy of percutaneous pedicle screw fixation for traumatic spine fractures [612]. Kim et al. recently demonstrated that percutaneous placement of pedicle screws as compared to open surgical technique is associated with less paraspinal muscle damage [4]. In addition, small comparison studies have demonstrated that percutaneous techniques are associated with less blood loss, shorter hospital stays, and improved peri-operative pain scores $[4,10,14]$. Despite these more recent studies, little is known about the efficacy of minimally invasive surgery, namely percutaneous pedicle screw fixation, for thoracolumbar spine fractures. 
Citation: Chaichana KL, la Garza-Ramos RD, Sciubba DM, Gokaslan ZL, Baaj AA (2012) Minimally Invasive Percutaneous Pedicle Screw Fixation for Thoracolumbar Spine Fractures: Case Report and Review of Literature. J Trauma Treat 1:134. doi:10.4172/2167-1222.1000134

Page 4 of 5

\begin{tabular}{|c|c|c|c|c|c|c|c|c|c|}
\hline Study & Year & $\begin{array}{c}\text { Number of } \\
\text { Patients }\end{array}$ & $\begin{array}{c}\text { Mean } \\
\text { (range) Age }\end{array}$ & Etiology & $\begin{array}{l}\text { S p i n a I } \\
\text { Location }\end{array}$ & Fracture type & $\begin{array}{l}\text { Neurological } \\
\text { symptoms }\end{array}$ & Complications & Outcome \\
\hline Present study & 2012 & 1 & 65 & Fall from height: 1 & T12: 1 & A3.3: 1 & None & None & $\begin{array}{l}\text { Pain improved score: } 6 \\
\text { Neuro improved: N/A } \\
\text { Kyphosis correction } 6^{\circ}\end{array}$ \\
\hline $\begin{array}{l}\text { Bironneau A, et } \\
\text { al. }{ }^{*}[7]\end{array}$ & 2011 & 24 & $58(20-88)$ & $\begin{array}{l}\text { Fall from height: } 16 \\
\text { MVC: } 8\end{array}$ & $\begin{array}{l}\text { T12: } 2 \\
\text { L1: } 12 \\
\text { L2: } 5 \\
\text { L3: } 2 \\
\text { L4: } 2 \\
\text { L5: } 1\end{array}$ & $\begin{array}{l}\text { A1: } 1 \\
\text { A2: } 1 \\
\text { A3.1: } 1 \\
\text { A3.2: } 10 \\
\text { A3.3: } 4 \\
\text { B2: } 3\end{array}$ & None & Hematoma: 1 & $\begin{array}{l}\text { Pain improved score: } 6.3 \\
\text { Neuro improved: N/A } \\
\text { Kyphosis correction: } 8.6^{\circ}\end{array}$ \\
\hline $\begin{array}{l}\text { Blondel } B \text {, et } \\
\text { al. }{ }^{*}[8]\end{array}$ & 2011 & 29 & $51(22-78)$ & Not specified & $\begin{array}{l}\text { T9: } 1 \\
\text { T11: } 3 \\
\text { T12: } 6 \\
\text { L1: } 13 \\
\text { L2: } 4 \\
\text { L5: } 2\end{array}$ & $\begin{array}{l}\text { A3.1: } 17 \\
\text { A3.2: } 3 \\
\text { A3.3: } 9\end{array}$ & None & None & $\begin{array}{l}\text { Pain improved score: } 5.6 \\
\text { Neuro improved: N/A } \\
\text { Kyphosis correction: } 11^{\circ}\end{array}$ \\
\hline Ni W, et al. [11] & 2010 & 36 & $43(19-58)$ & $\begin{array}{l}\text { Fall from height: } 24 \\
\text { MVC: } 12\end{array}$ & $\begin{array}{l}\text { T11: } 4 \\
\text { T12: } 8 \\
\text { L1: } 17 \\
\text { L2: } 7\end{array}$ & A3: 36 & None & & $\begin{array}{l}\text { Pain improved score: not } \\
\text { assessed } \\
\text { Kyphosis correction: } 9.1^{\circ}\end{array}$ \\
\hline $\begin{array}{l}\text { Agrawal } A \text {, et } \\
\text { al. [6] }\end{array}$ & 2010 & 1 & 16 & Fall from height: 1 & L4: 1 & A3.3:1 & Weakness: 1 & None & $\begin{array}{l}\text { Pain improved score: not } \\
\text { assessed } \\
\text { Neuro improved: } 1 \\
\text { Kyphosis correction: not } \\
\text { assessed }\end{array}$ \\
\hline $\begin{array}{l}\text { Palmisani M, et } \\
\text { al. }{ }^{*}[12]\end{array}$ & 2009 & 51 & $45(21-82)$ & $\begin{array}{l}\text { Fall from height: } 17 \\
\text { MVC: } 34\end{array}$ & $\begin{array}{l}\text { T1-T10: } 6 \\
\text { T11-L 1: } \\
\text { 31 } \\
\text { L2-L5: } 14\end{array}$ & $\begin{array}{l}\text { A1: } 20 \\
\text { A2: } 10 \\
\text { A3: } 27 \\
\text { B1: } 1 \\
\text { B2: } 3 \\
\text { C1: } 1 \\
\text { C2: } 2\end{array}$ & None & $\begin{array}{l}\text { Infection: } 1 \\
\text { Misplaced screw: } \\
1 \\
\text { Pseudoarthrosis: } 2\end{array}$ & $\begin{array}{l}\text { Pain improved score: not } \\
\text { assessed } \\
\text { Neuro improved: N/A } \\
\text { Kyphosis correction: } 6.2^{\circ}\end{array}$ \\
\hline Merom L [10] & 2009 & 10 & $42(21-63)$ & Not specified & $\begin{array}{lcc}\mathrm{N} & 0 & \mathrm{t} \\
\text { specified }\end{array}$ & A3.3: 10 & Not specified & None & $\begin{array}{l}\text { Pain improved score: not } \\
\text { assessed } \\
\text { Neuro improved: N/A } \\
\text { Kyphosis correction: not } \\
\text { assessed }\end{array}$ \\
\hline $\begin{array}{l}\text { Wild } \mathrm{MH} \text { et al. } \\
\text { [14] }\end{array}$ & 2007 & 10 & $49(31-65)$ & Not specified & $\begin{array}{lc}N & 0 \\
\text { specified }\end{array}$ & $\begin{array}{l}\text { A2.3: } 1 \\
\text { A3.1: } 6 \\
\text { A3.2: } 1 \\
\text { A3.3: } 2\end{array}$ & Not specified & None & $\begin{array}{l}\text { Pain improved score: not } \\
\text { assessed } \\
\text { Neuro improved: N/A } \\
\text { Kyphosis correction: } 7^{\circ}\end{array}$ \\
\hline $\begin{array}{l}\text { Maciejczak A et } \\
\text { al.* [9] }\end{array}$ & 2007 & 4 & $45(28-59)$ & $\begin{array}{l}\text { Fall from height: } 2 \\
\text { MVC: } 2\end{array}$ & $\begin{array}{l}\text { L2: } 2 \\
\text { L3: } 2\end{array}$ & A3.1: 4 & None & Pseudoarthrosis: 1 & $\begin{array}{l}\text { Pain improved score: not } \\
\text { assessed } \\
\text { Neuro improved: N/A } \\
\text { Kyphosis correction: } 11.6^{\circ}\end{array}$ \\
\hline
\end{tabular}

MVC: motor vehicle collision; N/A: not applicable, SD: standard deviation, VAS: visual analog scale, *vertebral body augmentation (kyphoplasty, interbody, etc.)

Table 1: Review of the literature on studies using minimally invasive, percutaneous pedicle screw fixation for traumatic thoracolumbar fractures.

This review of the literature demonstrates that minimally invasive surgery can be pursued in trauma patients. 166 patients underwent percutaneous placement of pedicle screws for traumatic thoracolumbar fractures. The fractures were disparate, but the most common fractures were burst fractures at the thoracoulumbar junction (T12-L1). Complications among these patients were rare, with only three patients reporting non-healing of the fracture site, one patient with wound infection, and one patient with a misplaced screw. The average surgery time was only 91 minutes, with an average blood loss of 95 milliliters. No patients incurred increased weakness, and the overwhelming majority had improved pain and kyphosis correction at last follow-up. These studies collectively show that these surgeries can be performed relatively quickly, with minimal blood loss, and minimal surgical morbidity. Merom et al. compared ten patients who underwent minimally invasive surgery with 10 patients who underwent convention posterior open surgery [10]. They report that patients who underwent minimally invasive surgery had less blood loss, operative times, wound infections, and post-operative pain scores as compared to open surgery [10]. However, no statistical analyses were made [10]. Wild et al. compared 11 patients with open surgery versus 10 patients with minimally invasive surgery [14]. Patients who underwent minimally invasive surgery had significantly less blood loss as compared to patients who underwent open surgery, but there was no difference in regards to operative time, loss of kyphosis correction, and functional outcomes between the two cohorts [14]. This technique is advantageous to expeditiously immobilize a thoracolumbar fracture with minimal or no kyphosis and no neurological deficits. The patients who may benefit the most from minimally invasive surgery are older patients and patients who sustained polytrauma. Older patients typically have more co-morbidities [20]. This increase in comorbidities makes it more difficult for them to tolerate long operative times and large blood loss [20]. Furthermore, elderly patients are more prone to spine fractures [20]. While the majority of the patients in this study were younger than 65 , some of the patient in these series wee in their late 80 s $[7,8,12]$. In addition, the patient in this study was 65 years old with rapid, progressive frontotemporal dementia with limited 
Citation: Chaichana KL, la Garza-Ramos RD, Sciubba DM, Gokaslan ZL, Baaj AA (2012) Minimally Invasive Percutaneous Pedicle Screw Fixation for Thoracolumbar Spine Fractures: Case Report and Review of Literature. J Trauma Treat 1:134. doi:10.4172/2167-1222.1000134

projected survival, and tolerated surgery well. Besides old age, patients with polytrauma may have less capacity to tolerate open surgeries [20]. $27 \%$ of the patients in this series had polytrauma. Patients who are older and/or have polytrauma are a subset of patients who may not tolerate open surgery. Minimally invasive surgery may be a viable option for these patients.

There are limitations to minimally invasive stabilization in the trauma setting. Only one patient in this series had neurological deficit [6]. Patients with neurological deficits where decompression is needed are not ideal candidates for only percutaneous pedicle screw fixation/ internal fixation. Additionally, patients with significant kyphosis or sagittal misalignment will not typically benefit from minimally invasive surgery. Percutaneous pedicle screw fixation can only correct mild kyphosis [12]. Also, bracing may be an option in healthy young individuals who will be compliant with wearing the brace and who have fractures with minimal loss of height and no kyphosis. Moreover, this study does not address the effects of prolonged instrumentation. There is concern that prolonged instrumentation can result in nonunion, which is why many advocate removing the hardware after healing of the fracture has been documented for six to twelve months [21]. The studies in this review did not evaluate the effects of prolonged instrumentation or whether fixation was affected following hardware removal. We agree that the hardware can be removed after bonehealing is seen since this was not a fusion technique. However, given this patient's overlying co-morbidities, this was not pursued. Lastly, long-term follow-up for patients who undergo percutaneous pedicle screw fixation for thoracolumbar fractures is typically limited. Only one study in this series had five-year follow-up times [14]. Studies with longer follow-up times are therefore needed to better evaluate outcomes for patients who undergo minimally invasive surgeries.

\section{Conclusion}

Thoracolumbar fractures are among the most common type of traumatic spine fractures. Management of unstable fractures is varied. Management typically involves open surgery with short-segment pedicle screw fixation. However, not all patients can tolerate this procedure because of the prolonged operating time, large volume blood loss, and paraspinal muscle injury and denervation, among others. The use of minimally invasive, percutaneous pedicle screw fixation has been increasing with advancements in surgical techniques and instrumentation. However, its use for traumatic thoracolumbar fractures has been limited to case reports and small case series. The present review demonstrates that minimally invasive surgery can be successfully achieved with minimal morbidity in neurologically intact patients with traumatic thoracolumbar fractures. Older patients and patients with polytrauma may most benefit from this approach.

\section{References}

1. Alpantaki K, Bano A, Pasku D, Mavrogenis AF, Papagelopoulos $P J$, et al. (2010) Thoracolumbar burst fractures: a systematic review of management. Orthopedics 33: 422-429.

2. Oner FC, Wood KB, Smith JS, Shaffrey Cl (2010) Therapeutic decision making in thoracolumbar spine trauma. Spine (Phila Pa 1976) 35: S235-244.

3. Foley KT, Gupta SK, Justis JR, Sherman MC (2001) Percutaneous pedicle screw fixation of the lumbar spine. Neurosurg Focus 10: E10.

4. Kim DY, Lee SH, Chung SK, Lee HY (2005) Comparison of multifidus muscle atrophy and trunk extension muscle strength: percutaneous versus open pedicle screw fixation. Spine (Phila Pa 1976) 30: 123-129.

5. Magerl FP (1984) Stabilization of the lower thoracic and lumbar spine with external skeletal fixation. Clin Orthop Relat Res 125-141.

6. Agrawal A, Mizuno J, Kato Y, Inoue T, Sano H (2010) Minimally invasive pedicle screw placement in a case of L4 fracture: case report with review of literature. Asian J Neurosurg 5: 64-69.

7. Bironneau A, Bouquet C, Millet-Barbe B, Leclercq N, Pries P, et al. (2011) Percutaneous internal fixation combined with kyphoplasty for neurologically intact thoracolumbar fractures: a prospective cohort study of 24 patients with one year of follow-up. Orthop Traumatol Surg Res 97: 389-395.

8. Blondel B, Fuentes S, Pech-Gourg G, Adetchessi T, Tropiano P, et al. (2011) Percutaneous management of thoracolumbar burst fractures: Evolution of techniques and strategy. Orthop Traumatol Surg Res 97: 527-532.

9. Maciejczak A, Barnas P, Dudziak P, Jagiełło-Bajer B, Litwora B, et al. (2007) Posterior keyhole corpectomy with percutaneous pedicle screw stabilization in the surgical management of lumbar burst fractures. Neurosurgery 60: 232-241.

10. Merom L, Raz N, Hamud C, Weisz I, Hanani A (2009) Minimally invasive burst fracture fixation in the thoracolumbar region. Orthopedics 32.

11. Ni WF, Huang YX, Chi YL, Xu HZ, Lin Y, et al. (2010) Percutaneous pedicle screw fixation for neurologic intact thoracolumbar burst fractures. J Spinal Disord Tech 23: 530-537

12. Palmisani M, Gasbarrini A, Brodano GB, De lure F, Cappuccio M, et al. (2009) Minimally invasive percutaneous fixation in the treatment of thoracic and lumbar spine fractures. Eur Spine J 18: 71-74.

13. Wang HW, Li CQ, Zhou Y, Zhang ZF, Wang J, et al. (2010) Percutaneous pedicle screw fixation through the pedicle of fractured vertebra in the treatment of type A thoracolumbar fractures using Sextant system: an analysis of 38 cases. Chin J Traumatol 13: 137-145.

14. Wild MH, Glees M, Plieschnegger C, Wenda K (2007) Five-year followup examination after purely minimally invasive posterior stabilization of thoracolumbar fractures: a comparison of minimally invasive percutaneously and conventionally open treated patients. Arch Orthop Trauma Surg 127: 335343.

15. Magerl F, Aebi M, Gertzbein SD, Harms J, Nazarian S (1994) A comprehensive classification of thoracic and lumbar injuries. Eur Spine J 3: 184-201.

16. Okuyama K, Abe E, Chiba M, Ishikawa N, Sato K (1996) Outcome of anterior decompression and stabilization for thoracolumbar unstable burst fractures in the absence of neurologic deficits. Spine (Phila Pa 1976) 21: 620-625.

17. Uchida K, Kobayashi S, Matsuzaki M, Nakajima H, Shimada S, et al. (2006) Anterior versus posterior surgery for osteoporotic vertebral collapse with neurological deficit in the thoracolumbar spine. Eur Spine J 15: 1759-1767.

18. Wood KB, Bohn D, Mehbod A (2005) Anterior versus posterior treatment of stable thoracolumbar burst fractures without neurologic deficit: a prospective randomized study. J Spinal Disord Tech 18: S15-23.

19. Roy-Camille R, Roy-Camille M, Saillant G, Demeulenaere C, Lelièvre JF (1972) Surgical therapeutic indications in vertebral injuries with spinal cord syndrome or cauda equina syndrome. Nouv Presse Med 1: 2165-2168.

20. Battie MC, Jones CA, Schopflocher DP, et al. (2012) Health-related quality of life and comorbidities associated with lumbar spinal stenosis. Spine J 12: 189-195.

21. Stavridis SI, Bücking $P$, Schaeren S, Jeanneret B, Schnake KJ (2010) Implant removal after posterior stabilization of the thoraco-lumbar spine. Arch Orthop Trauma Surg 130: 119-123. 